\title{
Modeling the microclimate inside a vessel in in vitro culture : vessel with agar
}

\author{
Yao TcheTche ${ }^{1 *}$, Djézia F-X. Bouo Bella ${ }^{1}$, Huguette Sallamon ${ }^{2}$, Alain Coudert² \& Harumi Isaka ${ }^{3}$ \\ 'Université d'Abobo-Adjamé, UFR des Sciences Fondamentales et Appliquées, 2 BP 801 Abidjan 2, Côte d'Ivoire. \\ ${ }^{2}$ Faculté des Sciences, Université d'Avignon et des Pays de Vaucluse, 33 rue Louis Pasteur, 84470 Avignon, France. \\ ${ }^{3}$ Laboratoire de Météorologie Physique, Université Blaise Pascal, 24 avenue des Landais, 63177 Aubière, France. \\ *Author to whom correspondence should be addressed (E-mail: tchetche_yao@yahoo.fr) \\ Reçu le 08-11-2005, accepté le 27-10-2006.
}

\begin{abstract}
Numerical simulations show that variations in vessel internal humidity was sensitive to transfer coefficient, climatic conditions within the growth chamber, evaporation and condensation of water vapor on the walls of the vessel. The variations in water vapor pressure deficits (VPD) (low during the nyctiperiod and high during the photoperiod) were well explained by a free convection model, which took into account temperature differences. Finally, the results show the necessity to construct containers with variable openings and growth chambers in which bioclimatic conditions can be controlled.
\end{abstract}

Keywords : Agar, in vitro culture, microclimate, modeling, transfer coefficient.

\section{Résumé}

Modélisation des conditions d'environnement des bocaux de culture in vitro : Bocaux contenant uniquement de la gélose

Les simulations numériques révèlent que les variations de l'humidité interne ont été sensibles au coefficient d'échange de vapeur d'eau, aux conditions climatiques de la chambre de culture et aux phénomènes d'évaporation et de condensation de vapeur d'eau sur les parois des bocaux. Par ailleurs, il a été établi que le "créneau» de déficit de pression de vapeur (DPV) de l'air intérieur (palier de DPV faible en nyctipériode et palier de DPV élevé en photopériode) a été bien imité en mode convectif libre qui tient compte des écarts de températures. Ainsi, ces résultats montrent la nécessité de construire des récipients à ouverture variable et des chambres de culture dans lesquelles les facteurs bioclimatiques des plantes peuvent être maîtrisés.

Mots clés : Agar, culture in vitro, microclimat, modélisation, coefficient d'échange.

\section{Introduction}

In vitro culture techniques are usually used in the field of horticulture. They lead to vegetative multiplication of plant tissue that allows the preservation of the main characters of the original plants. Even if the usefulness of these methods is well recognized, some problems remain. It has been shown that environmental conditions in growth chambers, mainly light intensity, temperature and relative humidity, have a strong influence on the growth and development of various explants (Nguyen et al., 1998 ; Jao \& Fang, 2004). Although numerous studies have been conducted with light intensity and photosynthetic activity of plantlets (Kosai et al., 1988; Pospisilova et al., 1992 ; Jorge et al., 2001), temperature, humidity and water status (Ohyama et al., 2000) received little attention. Hypothesis proposed to explain agar induced variations in vitro includes 
the water potential of the medium (Debergh \& Maene, 1983). The author had shown earlier (Debergh et al., 1981) that a decrease in vessel temperature resulted in a subsequent decrease in relative humidity inside the container in order to facilitate acclimatization in the green-house. Later, it was empirically shown that the regulation of relative humidity in growth chambers could induce plantlets growth. These observations had been linked to experimental measurements of relative humidities inside the vessels and could explain changes observed in plantlets growth (Sallanon \& Coudret, 1990 ; Sallanon \& Mazière, 1992).

Most studies up to date have dealt with the physical conditions that were mainly limited to an analysis of the thermal behavior of the culture vessels (Chasseriaux, 1986 ; Urban et al., 1990). But, in order to optimize the production of vitroplants, it is necessary to have better understanding of the physical phenomena that take place inside the jars.
This study aims to develop a model that will help to explain some experimental results obtained by Sallanon and Coudret (1990), and, to estimate the different parameters and processes determining the atmospheric conditions inside the vessels, particularly moisture.

\section{Material and methods}

The apparatus consisted in glass jar $(10 \mathrm{~cm}$ diameter ; $11 \mathrm{~cm}$ height containing an agar medium of $2 \mathrm{~cm}$ thick) assumed not to be tightly shut. The jars with agar were introduced into a culture room where temperature and moisture were controlled. The agar and the inner sides of the vessel received light fluxes, which were partially absorbed. Heat and water were allowed to exchange freely between the air inside the jar and the agar medium, the inner-sides and the air inside the culture room. The exchange of matter with the surrounding atmosphere was achieved through a hole between the inner-side and the lid (Fig. 1).

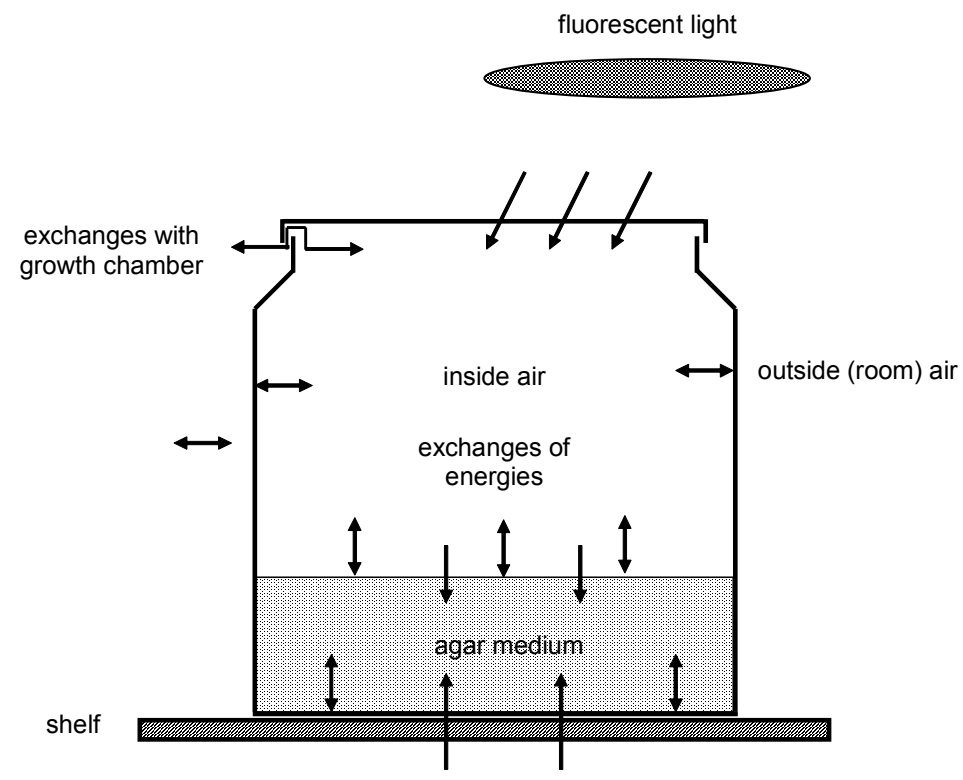

Figure 1 : Schematic view of a growth vessel and interactions between its different parts and internal and external air.

\subsection{Inner atmosphere of the jar}

The air inside the jar was characterized by temperature and moisture conditions. This temperature was assumed to be uniform, but could vary through convective exchanges with the agar and the inner sides of the jar. Absorption due to visible and infrared radiation was neglected (1) :

$$
\mathrm{m}_{\mathrm{a}} \mathrm{C}_{\mathrm{p}_{\mathrm{a}}} \frac{\mathrm{dT}_{\mathrm{in}}}{\mathrm{dt}}=\mathrm{s}_{1} \mathrm{Ch}\left(\mathrm{T}_{\mathrm{gs}}-\mathrm{T}_{\mathrm{in}}\right)+\mathrm{s}_{2} \mathrm{Ch}\left(\mathrm{T}_{\mathrm{pa}}-\mathrm{T}_{\mathrm{in}}\right)
$$


Where ,

Tin, Tpa , Tgs : air temperature, temperature of the inner side of the vessel and the agar surface, respectively,

ma , Cpa : mass and specific heat of the inner air, respectively,

$\mathrm{Ch}$ : heat convection exchange coefficient,

$s_{1}, s_{2}$ : agar and inner vessel side surfaces, respectively.

The volumic mass of water vapor inside the jar varied first because of water vapor exchange with the ambient atmosphere (due to molecular diffusion through the hole, dilatation and contraction phenomena because of temperature variations), and second, due to water evaporation and condensation on the agar and on the inner vessel sides. Thus, the quantity of water vapor can be expressed as (2) :

$$
M_{v}=v \rho_{\text {in }}
$$

Where $v$ is the air volume in the jar and, rin the volumic mass of the water vapor in the jar. The variation due to molecular diffusion can be written as (3):

$$
\left.\frac{\mathrm{dMv}}{\mathrm{dt}}\right|_{\text {diffusion }}=\mathrm{s}_{1} \lambda \mathrm{D}\left(\rho_{\mathrm{ex}}-\rho_{\mathrm{in}}\right) / \mathrm{L}
$$

Where : rex and $D$ are respectively the volumic mass of water vapor in the surrounding atmosphere, and the molecular diffusibility of water vapor in the air. L and I are related respectively to the length and the width of the hole through which the exchange took place.

The exchange due to temperature variations, atmospheric pressure was assumed to be (4):

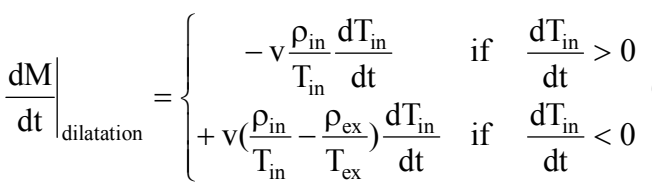

Condensation and evaporation phenomena that took place at the surface of the nutritive medium and on the inner-sides of the jar can be modeled by equation (5) :

$$
\left.\frac{\mathrm{dMv}}{\mathrm{dt}}\right|_{\text {cond/evap }}=\mathrm{s}_{1} \mathrm{Ch}\left(\rho_{\mathrm{gs}}-\rho_{\text {in }}\right)+\mathrm{s}_{2} \operatorname{Ch}\left(\rho_{\mathrm{pa}}-\rho_{\text {in }}\right) \text { (5) }
$$

where, rgs and rpa correspond to the volumic mass of water vapor of the agar and the innersides surface of the jar, respectively. Considering the volumic mass of water vapor inside the vessel, the equation can be rewritten (6) :

$$
\frac{\mathrm{dMv}}{\mathrm{dt}}=\left.\frac{\mathrm{dMv}}{\mathrm{dt}}\right|_{\text {diffusion }}+\left.\frac{\mathrm{dMv}}{\mathrm{dt}}\right|_{\text {dilatation }}+\left.\frac{\mathrm{dMv}}{\mathrm{dt}}\right|_{\text {cond/evap }}
$$

A description of the moisture condition in the inner-side of the vessel requires that the impurities, and the chemical compounds that were responsible for the decrease in water vapor tension be considered. Thus, a fictitious coefficient $(h » 1)$, also known as degree of 'clearness' and which links the usual calculated saturated vapor pressure at the surface of a flat with pure water (7):

$$
\rho_{p a}=\eta\left(\rho_{p a}\right)_{s a t}
$$

\subsection{Vessel wall}

The vessel wall was characterized by its temperature, which was assumed to be uniform. But this temperature varied from convective exchanges with the agar and the inner side of the vessel, as well as from absorption of visible and infrared radiations (8):

$$
\begin{aligned}
\mathrm{m}_{\mathrm{p}} \mathrm{Cp}_{\mathrm{p}} \frac{\mathrm{dT}_{\mathrm{pa}}}{\mathrm{dt}=} & \mathrm{a}_{\mathrm{p}} \mathrm{s}_{2}^{*} \mathrm{R}_{0}+\sigma_{\mathrm{s}} \mathrm{s}_{1}^{*}\left(\mathrm{~T}_{\mathrm{gs}}^{4}-\mathrm{T}_{\mathrm{pa}}^{4}\right) \\
& +\mathrm{s}_{2} \mathrm{Ch}\left(\mathrm{T}_{\mathrm{in}}-\mathrm{T}_{\mathrm{pa}}\right)+\mathrm{s}_{2}^{*} \mathrm{Ch}\left(\mathrm{T}_{\mathrm{ex}}-\mathrm{T}_{\mathrm{pa}}\right) \\
& +\mathrm{s}_{1} \mathrm{C}_{\mathrm{nd}}\left(\mathrm{T}_{\mathrm{ex}}-\mathrm{T}_{\mathrm{pa}}\right)+\mathrm{s}_{1} \mathrm{C}_{\mathrm{ndg}}\left(\mathrm{T}_{\mathrm{N}-\mathrm{1}}-\mathrm{T}_{\mathrm{pa}}\right) \\
& +\mathrm{dv} \frac{\mathrm{d} \mathrm{M}_{\mathrm{cp}}}{\mathrm{dt}}
\end{aligned}
$$

Where,

$m p$, Cpp : mass and specific heat of the glass of the vessel,

$a_{p}, s_{s}$ : absorption coefficient of the glass in visible and Stefan-Boltzman constant,

$R O$ : radiative flux due to light,

$s_{1}{ }^{*}$ : exchange surface between agar and the walls correlated by form factors,

$s_{2}{ }^{*}$ : exchange surface between external air and vessel walls,

$C h, C h^{*}$ : exchange coefficients of heat by convection, inside and outside the vessel, respectively,

Cnd, Cndg: heat exchange coefficients by 
conduction between the wall and the shelf, and between the wall and the agar, respectively,

$T_{N-1}$ : temperature at the last but one point of the grid in agar.

$L v$ : latent heat of evaporation

$M c p$ : condensated or evaporated water.

Moreover, even if heat conduction exchange coefficients can be chosen for the simulations, those of thermal and hydric transfers by convection must be defined. For external exchanges, a model of forced convection, where exchange coefficient is a function of air speed was used. Usually, this coefficient is defined by the Reynolds and Prandlt dimensionless numbers, but the simplified formulation proposed by Oke (1978) was used (9) :

$$
C h^{*}=C_{m} U
$$

Where, $C_{m}$ and $U$ are characteristic constant and air speed, respectively.

For the internal convection of the vessel, two cases were considered : first, a forced convection which is not realistic in our study, and second, a model of free convection which takes into account differences in temperature at the agar surface, the walls and the air inside the vessel. In order to simplify the problem, a coefficient representing a linear combination of exchange coefficients between the agar and air $\left(\mathrm{Ch}_{1}\right)$ and between the walls and air $\left(\mathrm{Ch}_{2}\right)$ was used. The equation can then be written as follows (10):

$$
C h=a_{1} C h_{1}+a_{2} C h_{2}
$$

The exchange coefficients were estimated using Mc Adams (1961) equations (11).

$C h_{1}=b A\left|T_{g s}-T_{i n}\right|^{1 / 4} \quad C h_{2}=b A\left|T_{p a}-T_{i n}\right|^{1 / 4}$

where $A$ is a function which is characteristic of the length of the exchange surface and the thermodynamic properties of air.

Coefficients $a_{1}, a_{2}$ and $b$ in equations 10 and 11 were adjusted so as experimental data and simulations are in agreement.

Moreover, $b$ assumed two values depending on whether agar surface was warmer $(0,25)$ or not $(0,11)$ than the air inside the vessel. These values were inferior to those proposed by Mc Adams (1961) which were 0,54 with warm agar and 0,27 with cold agar. This shows that exchanges were weak in our study.

\subsection{Agar medium}

Agar medium is not supposed to be uniform as far as temperature and humidity are concerned. The medium is the center of simultaneous heat and mass transfer. But because of a lack of data in the literature to define agar medium, these transfers were described using the theoretical model applied to porous media (Vauclin et al., 1979 ; Dunand, 1982). The agar is considered to be a multilayer system in which water moves due to potential and temperature gradients (12) :

$\mathrm{C}_{\mathrm{h}} \frac{\partial \mathrm{h}}{\partial \mathrm{t}}=\frac{\partial}{\partial \mathrm{z}}\left[\mathrm{K}_{\mathrm{h}}\left(\frac{\partial \mathrm{h}}{\partial \mathrm{z}}-1\right)+\mathrm{D}_{\mathrm{T}} \frac{\partial \mathrm{T}}{\partial \mathrm{z}}\right]$

where $h$ is the pressure head and $T$ the temperature of the medium. The agar medium was considered to be semi-transparent to visible radiation. So, 3 fluxes were used in the transientheat flow equation : one due to conduction and the other two induced by light on both the bottom and the top of the vessel (13).

$C_{c} \frac{\partial T}{\partial t}=\frac{\partial}{\partial z}\left[\lambda \frac{\partial T}{\partial z}\right]+\left(1-r_{g}\right) R_{0}^{*} \exp (-\alpha z)+R_{0}^{*} \exp \left(-\alpha\left(z_{n}-z\right)\right)$

where,

$r g, a$ : reflexion and attenuation coefficients of the medium, respectively,

$\mathrm{zn}$ : thickness of the medium,

$\mathrm{R}_{0}^{*}$ : energy flux (due to illumination) reaching the top of the medium.

The transport coefficients (Ch : capillary capacity $; \mathrm{Kh}$ : hydraulic conductivity; $\mathrm{D}_{\mathrm{T}}$ : thermal moisture diffusivity; $\mathrm{Cc}_{\mathrm{C}}$ : heat capacity ; I : apparent thermal conductivity) were determined with the formula used for porous medium (i.e. soils) available in the literature and, particularly, soils containing expending clays which appear to have the same behaviour as the agar medium (Campbell, 1974 ; Mc Cumber, 1980).

In addition, the agar medium can exchange energy with the environment. At the bottom of the container, water transport is nil and temperature is equal to that of the glass. At the upper boundary, where agar is in contact with the internal air, a boundary problem arises and energetic exchanges can be of 4 types : 
$1 /$ Net radiative flux at the surface $(\mathrm{Rn})$, expressed as sum of the radiative flux absorbed by the first layer of the medium and the net infrared radiation using the following formula (14) :

$$
\mathrm{R}_{\mathrm{n}}=\left(1-\mathrm{r}_{\mathrm{g}}\right)\left(1-\mathrm{R}_{0}^{*} \exp \left(-0 z_{1}\right)\right) \sigma_{s} \mathrm{~F}\left(\mathrm{~T}_{\mathrm{pa}}^{4}-\mathrm{T}_{\sigma}^{4}\right)(14)
$$

where, $F$ is a form factor.

2/ Sensible heat flux $(H)$, written as (15):

$$
\mathrm{H}=\rho_{\mathrm{a}} \mathrm{C}_{\mathrm{a}} \mathrm{Ch}\left(\mathrm{T}_{\mathrm{g}}-\mathrm{T}_{\mathrm{in}}\right)
$$

with $\rho_{\text {a }}$ the air density.

3/ Latent heat flux due to surface evaporation or condensation (LvEv), expressed as (16) :

$$
\mathrm{L}_{\pi} \mathrm{E}_{\pi}=\mathrm{L}_{\pi} \frac{\mathrm{M}}{\mathrm{R}} \mathrm{Ch}\left[\frac{\mathrm{E}_{\boldsymbol{g}}}{\mathrm{T}_{\vec{g}}}-\frac{\mathrm{E}_{\text {in }}}{\mathrm{T}_{\dot{\mathbf{n}}}}\right]
$$

where, Egs and Ein represent the partial pressure of water vapor at the surface of the medium and the internal air in the bottle, respectively, Lv the latent heat of evaporation, $\mathrm{R}$ the gas constant and $\mathrm{M}$ the molecular weight of water.

4/ Heat flux into the medium due to conduction (S) written as (17):

$$
S=-\lambda_{S}\left(\frac{\partial T}{\partial z}\right)_{z=0}
$$

where, Is is the thermal conductivity at the surface of the medium.

The first condition of the medium-atmosphere interface is the conservation of energy, which may be written as (18):

$$
\mathrm{R}_{\mathrm{n}}=\mathrm{H}+\mathrm{L}_{\pi} \mathrm{E}_{\pi}+\mathrm{S}
$$

The second condition is the mass conservation law for water, expressed with the following equation (19):

$$
E_{v}=\left[K_{h}\left(\frac{\partial h}{\partial z}-1\right)+D_{T} \frac{\partial T}{\partial z}\right]_{z=0}
$$

\section{Discretisation and numerical schemes}

The mass and heat transfer equations, have been solved using a total implicit finite differences scheme (Vauclin et al., 1979). The NewtonRaphson method has been used for simultaneous resolutions of the discrete equations of mass and energy at the surface of the agar. To solve the differential equations of the different quantities (temperatures, volumic mass of water vapor inside the jar), the four-order Runge Kutta numerical method was used.

\section{Results and discussion}

In order to study the thermal and moisture status of the culture vessels, simulations techniques have been employed by varying two parameters : the degree of "pureness» $h$ and the transfer coefficient $\mathrm{Ch}$. The simulations conditions were the same as those experimentally used by Sallanon and Coudret (1990) (Fig. 2). The vessels were kept in a growth chamber adjusted to provide day/night temperatures of $26 / 22^{\circ} \mathrm{C}$, a relative humidity of $30 \%$ and a 16 -hour light period with a flux density of $11 \mathrm{Wm}^{-2}$.

Daily variations in agar medium temperature, container walls and external/ internal atmosphere revealed two periods associated with two transitions phases (cooling and heating).

With $\mathrm{h}$ equal 0.998 , we tested the type of convection, which took place in the vessel. Figure 3 presents the graph of the simulated vapor pressure deficit (VPD) in the bottles with models of free and forced convections. Generally, these curves show variations between thermoperiods. Two observations could be made from the first graph obtained from forced convection : a high increase in air VPD during temperature rise, a low difference between the photoperiod and the stable stage of the nyctiperiod.

With the free convection model, these two observations were disregarded and the variations in vapor pressure presented a stable stage corresponding to the nyctiperiod and the photoperiod. The variations in VPD were quite reproducible; they were low during the nyctiperiod and high during the photoperiod.

During cooling and heating phases, the VPD decreases due to the increase in transfer coefficients, taking into account differences in temperature. The variations in internal humidity 
were sensitive to the transfer coefficient. This parameter is very important and therefore must be well understood. But, its determination is complex and delicate, because transfers are weak and enclosed atmosphere is not entirely homogenous. Humidity, measured at three different levels in the vessel show that air-VPD, was generally greater in the middle than in the other areas of the vessel.

Although the water environment in in vitro culture should be considered as specific, these results point out that the air inside the bottles is not completely saturated during the day. The variations in air VPD corresponded to those of relative humidity $(4 \%)$, which, although weak, can affect plant growth. More precisely, the comparison between the simulated variations in air VPD and experimental data was possible by adjusting the characteristic parameters of the agar medium, the transfer coefficients and the leak (the exchange of water vapor with the outside air). The latter was obtained by adjusting bottle opening size.

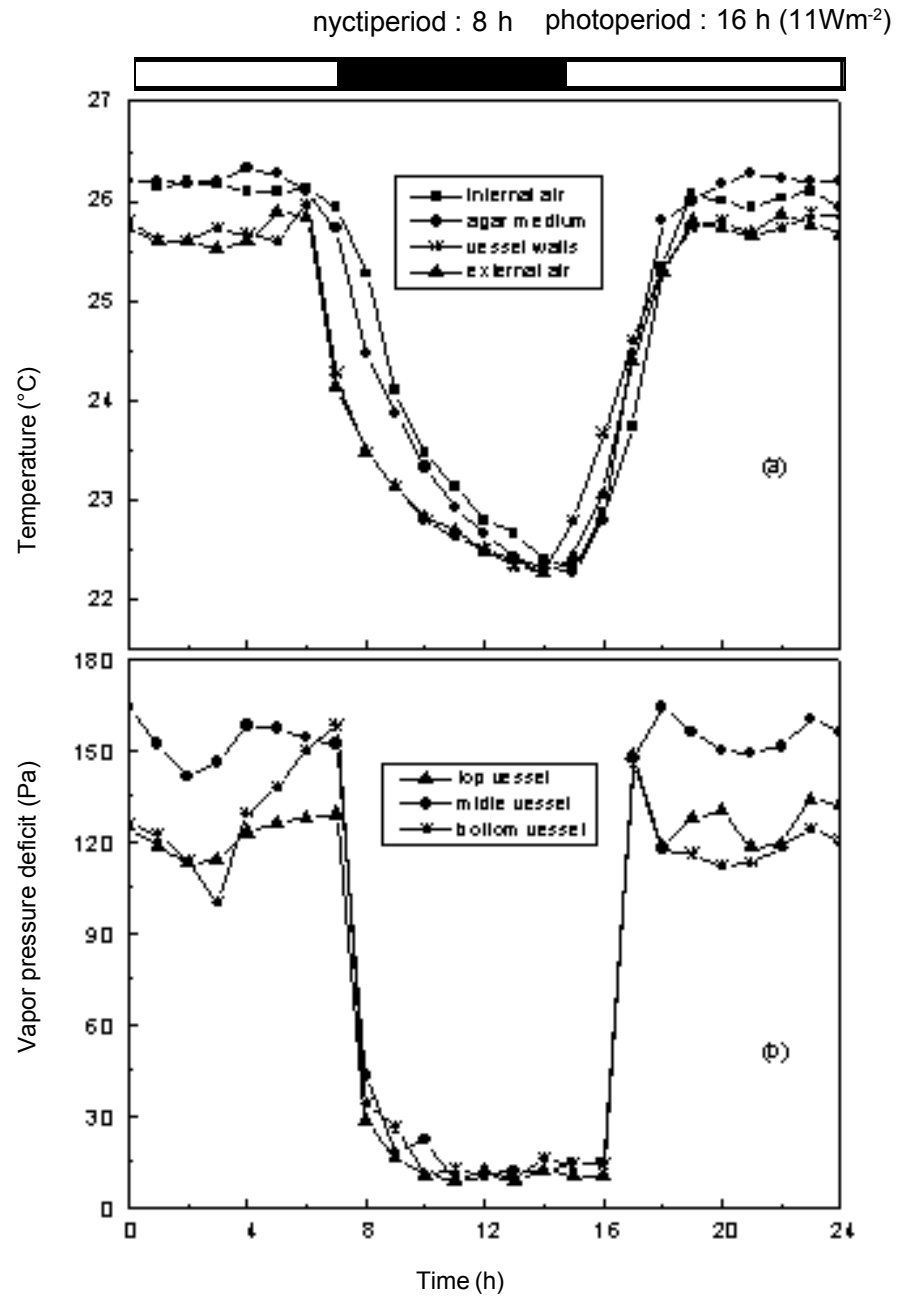

Figure 2 : Daily changes in (a) temperatures, (b) vapor pressure deficits inside a closed (growth) vessel. 


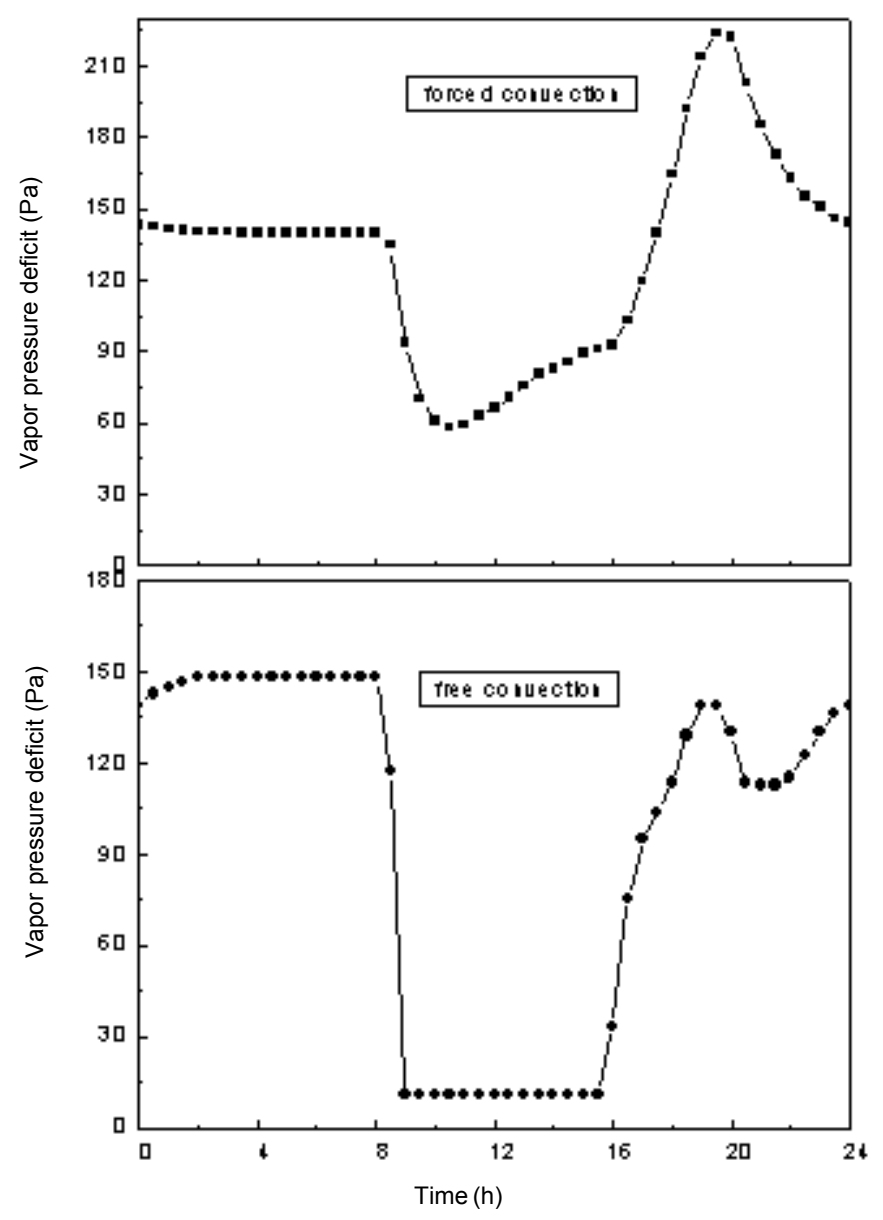

Figure 3 : Simulated daily changes in vapor pressure deficits inside a growth vessel.

Also, water loss after 21 days of culture were in close agreement : $3.5 \mathrm{~g}$, calculated using the model and 2 to $6 \mathrm{~g}$ from experimental data (Sallanon, 1990). In addition, with free convection model, the effects on air humidity due to condensation and evaporation of water on the walls of the vessels, have been examined. Figure 4 shows daily variations in air VPD and the tickness of condensed water for 3 values of the so-called degree of «pureness». The condensation of water vapor was quick that the degree of "pureness» decreased because of the existence of gaseous impurities on vessel walls. This condensation drew water vapor from inside of the vessel in such a way that the stable stage of air VPD during the nyctiperiod became significantly high. When evaporation on the walls started, the relative humidity in the bottle increased, especially during the rise in temperature. In our model, we supposed that condensed water did not flow freely. This hypothesis was partially true because a partial flow of water could have occurred, thereby rehydrating the agar.

Although, experimental data was not available to illustrate this point of view, the present model and the simulations thereto point out the importance of such a phenomenon. 
The simulations made by alternating temperatures $\left(22 / 26^{\circ} \mathrm{C}\right)$ and by cooling $\left(22.5^{\circ} \mathrm{C}\right)$ the bottom of a tightly closed bottle are presented in figure 5. Two important observations can be made from this plot:

- the humidity was very low during the photoperiod (VPD $450 \mathrm{~Pa}$ ) ;
- the humidity tended to be saturated during part of the cooling and warming up phases. It is worth noting that it is impossible to have these two tendencies at the same time by increasing leaks in the bottles (Debergh et al., 1981; Vanderschaeghe \& Debergh, 1988).

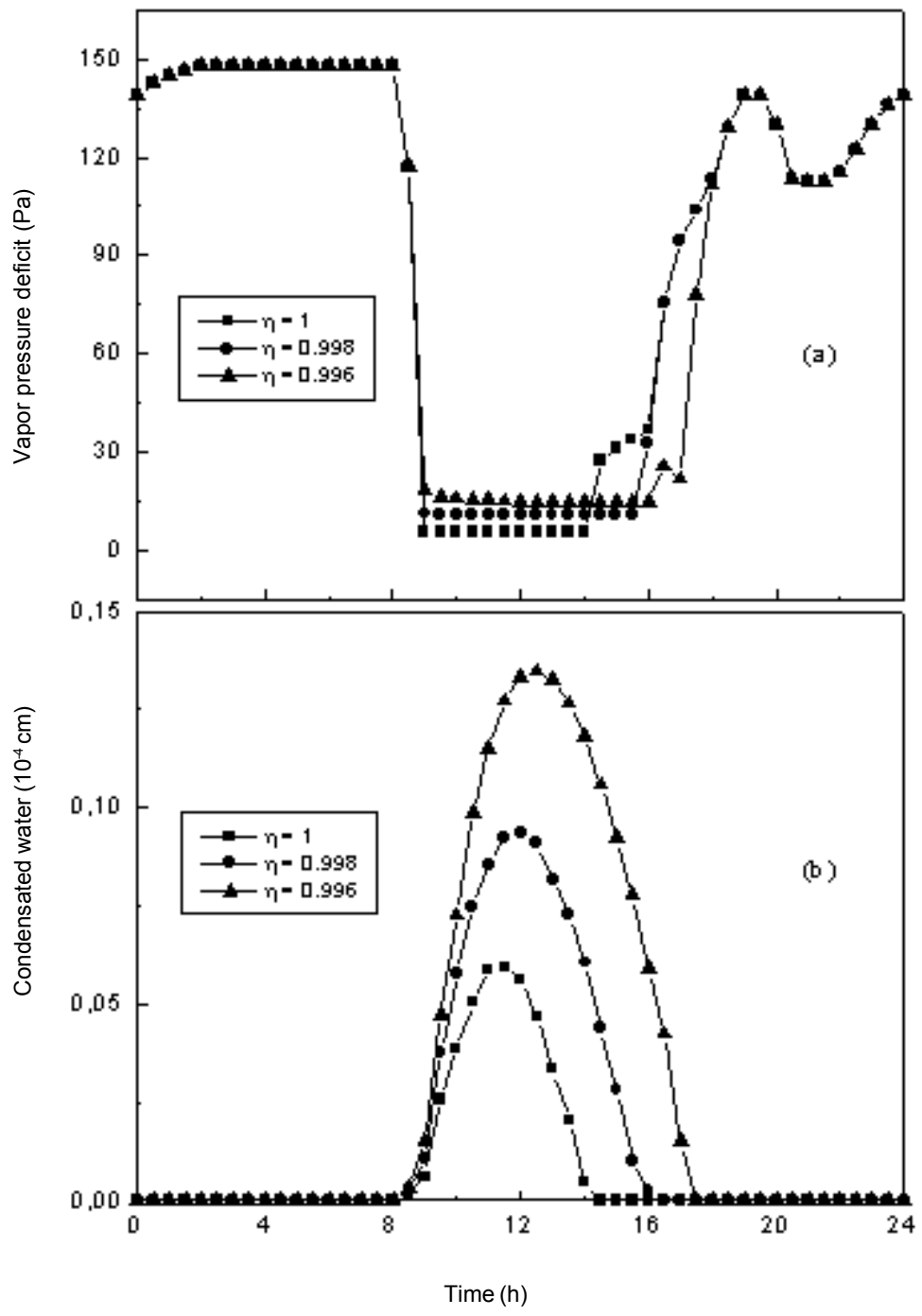

Figure 4 : Daily changes in (a) vapor pressure deficits inside closed (growth) vessels, (b) water thickness on vessel walls simulated in free convection with 3 values of degree of «pureness 


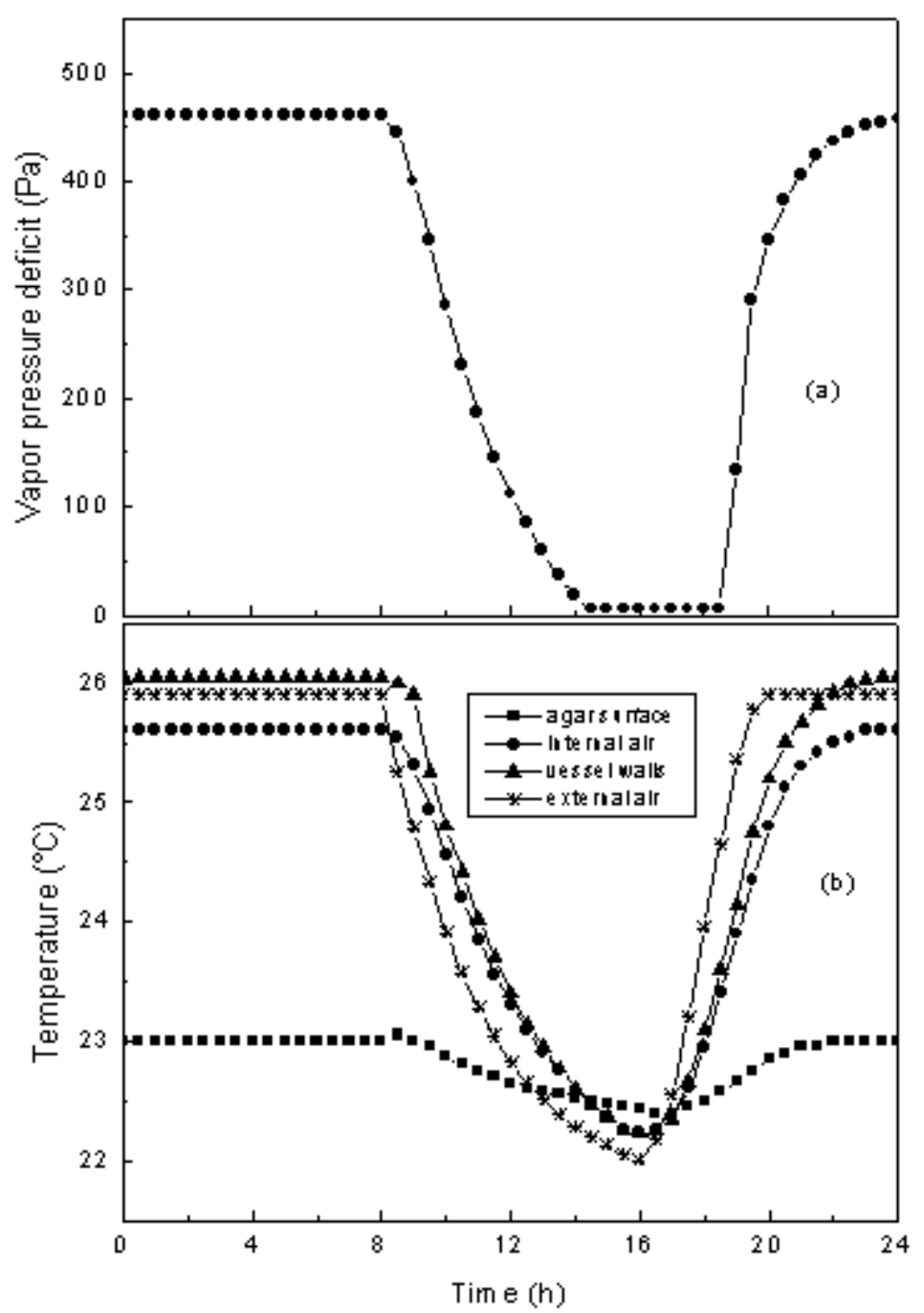

Figure 5 : Daily changes in (a) vapor pressure deficit inside a closed (growth) vessel, (b) temperatures obtained with a bottom cooling model

\section{Conclusion}

Overall, one should retain that beyond the feasibility of the model, the simulations permitted to evaluate the impact of leaks and exchanges on environment, which have an influence on internal air. In practice, we can recommend the use of a bottle with adjustable openings to control leaks and also, take into account the type of shelf or the thermal conditions at the bottom of the vessel. The model will allow construction of containers with variable openings and even growth chambers in which bioclimatic factors and their influences on the development of plants will be apprehended.

Also, the model developed in this study permits to justify notably the far technology known as "bottom cooling», which consists in the cooling of the bottom of the vessels.

Finally, this model allows to integrate other 
parameters such as $\mathrm{CO} 2$ and ethylene into the model and to study the rate of variations of these compounds. But, prior to that, in a next experiment, we are going to enclose plantlets as a water vector, and show the contribution of their water reserves.

\section{References}

Campbell G.S., 1974. A simple method for determining unsaturated conductivity from moisture retention data. Soil Sci. 117 : 311-314.

Chasseriaux G., 1986. Contribution à l'étude du microclimat à l'intérieur des bocaux de culture in vitro. P. H. M. Rev. Hort. 268 : 29-32.

Coudret A. \& Sallanon H., 1992. Relations entre la physiologie, la morphogenèse des vitroplants et leur environnement gazeux. Bull. Soc. Bot. Fr. 139 : 397-411.

Debergh P., Harbaouj Y \& Lemeur R., 1981. Mass propagation of global artichoke (cynara scolymus). Evaluation of different hypotheses to overcome vitrification with special reference to water potentiel. Phys. Plant. 53 : 181-187.

Debergh P.C.\& Maene L.J., 1983. Contribution of tissue culture techniques to horticultural research and production. Acta Hort. 131: 23-38.

Dumand A, 1982. Modélisations des transferts thermiques et hydriques dans le sol. Application à l'extraction d'énergie thermique par pompe à chaleur couplée à un réseau horizontal de tuyaux enterrés. Thèse de Docteur - Ingénieur, Université de Grenoble, France. 300 pp.

Jao R.C. \& Fang W., 2004. Effect of frequency and duty ration on the growth of potato plantlets in vitro using light-emitting diodes. Hort. Sci. 39 : 375-379.

Jorge M.A.B., Robertson A.I, Mashingaidze A.B. \& Keogh E., 2001. Distinguishing the effects of light and temperature variations on the growth, development, multiplication potential and ex vitro survival rates of in vitro cassava. Ann. Appl. Biol. 138 (3) : 363-370.
Kosai T., Koyama Y. \& Watanabbe I., 1988. Multiplication of patato plantlets in vitro with free medium under high photosynthetic photon flux. Acta Hort. 230 : 121-127.

Mc Adams W.H.., 1961. Transmission de la chaleur. Paris, France : Dunod. 585 pp.

Mc Cumber M., 1980. A numerical simulation of the influence of heat and moisture fluxes upon mesoscale circulation. PhD. University of Virginia, Charlottesville, USA. 255 pp.

Nguyen Q. T.\& Kozai T., 1998. Environmental effects on the growth of plantlets in micropropagation. Environ. Cont. Biol., 36 : 5975.

Oke T.B., 1978. Boundary layer climates. London, England: Methuen \& Co. $150 \mathrm{p}$

Ohyama K., Yoshinaga \& Kozai T., 2000. Energy and masse balance of a closed-type transplant production system (part2) - water balance. J. High Technol. Agric. 12 (4), 225-231.

Pospisilova J., Solarova \& Catsky J., 1992. Photosynthetic responses to stresses during in vitro cultivation. Photosynthetica, 26 (1) : 3-18.

Sallanon H. \& Coudret A., 1990. Flux d'eau entre vitroplants et atmosphère en micropropagation. C. R. Acad. Sci. Paris 310 : 607-613.

Sallanon H. \& Mazière Y., 1992. Influence of growth room and vessel humidity on in vitro development of rose plants. Plant Cell Tiss. Org. Cult., 30 : 121-125.

Urban L. \& Jaffrin A. 1990. Steady state thermal conditions inside plant tissue culture vessels submitted to a constant level of irradiation. Biotronics 19 : 71-81.

Vanderschaeghe A. M. \& Debergh P. C. 1988. Automation of tissue culture manipulations in the final stages. Acta Hort., 227 : 399-401.

Vauclin M., Hverkamp R. \& Vachaud G., 1979. Résolution numérique d'une équation de diffusion non linéaire. Grenoble, France: Presses universitaires Grenoble. 183 pp. 